\title{
Anxiety and depression, cognitive coping strategies, and health locus of control in patients with digestive system cancer
}

\author{
Marta Kulpa ${ }^{1}$, Mariola Kosowicz², Beata J. Stypuła-Ciuba³, Dorota Kazalska² \\ ${ }^{1}$ Department of Medical Psychology, Psychooncology Clinic, Medical University of Warsaw, Warsaw, Poland \\ ${ }^{2}$ Psychooncology Clinic, Oncology Centre of the M. Skłodowska-Curie - Institute, Warsaw, Poland \\ ${ }^{3}$ Department of Oncology and Internal Medicine and Pain Clinic, Oncology Centre of the M. Skłodowska-Curie - Institute, \\ Warsaw, Poland
}

Prz Gastroenterol 2014; 9 (6): 329-335

DOI: $10.5114 /$ pg.2014.47895

Key words: anxiety, depression, coping strategies, cancer.

Address for correspondence: Beata J. Stypuła-Ciuba MD, Department of Oncology and Internal Medicine and Pain Clinic, Oncology Centre of the M. Skłodowska-Curie - Institute, 5 Roentgena St, 02-781 Warsaw, Poland, phone: +48 606201 218, fax: +48 225462232 , e-mail: bciuba@coi.waw.pl

\begin{abstract}
Introduction: Contemporary psycho-oncology focuses on the study of the psychological determinants of the functioning of cancer patients. Among the psychological factors that significantly affect the functioning of the patients are anxiety and depressive disorders.

Aim: To assess the psychological functioning of patients with digestive system cancer in the cancer-treating process and to develop guidelines for psychological care dedicated to this group of patients based on the results of the study.

Material and methods: A total of 69 patients aged 23 to 91 (average 56) years with digestive system cancer treated in the Gastroenterology Cancer Clinic in the Institute of Oncology in Warsaw were examined using HADS, Mini-MAC, and MHLC. The results were analysed using statistical tests and correlation analysis. Another 532 patients from other wards formed the reference group.

Results: Measured HLC, anxiety, and depression did not differ significantly from the overall patient population. The investigation of the relationships between anxiety and depression and mental adjustment to cancer showed a positive correlation between anxiety and depression and anxious preoccupation and hopelessness-helplessness, and negative correlation between anxiety and depression and fighting spirit.

Conclusions: The obtained research results on the correlation of anxiety and depression with health locus of control show that the lower the severity of anxiety and depression, the higher the severity of internal health locus of control. The results confirm the necessity of psychological support forcancer patients showing evidence of destructive attitudes and external health locus of control, so that the severity of anxiety-depressive disorders can indirectly be reduced.
\end{abstract}

\section{Introduction}

Cancer is one of the most frequent diseases (second only to cardiac diseases) and is among the main causes of disability worldwide [1]. Contemporary psycho-oncology focuses on the study of the psychological determinants of the functioning of cancer patients to find answers about ways of coping with the disease, helping the healing process, facilitating the establishment of a good therapeutic relationship, delaying the progression of the disease, and facilitating the process of adapting to difficult situations

Among the psychological factors that significantly affect the functioning of the patients are anxiety and depressive disorders. Depression accompanying neoplastic disease is referred to as secondary depression, reactive in response to a difficult, stressful event that exceeds the adaptive capabilities of a person [2, 3]. Depression negatively affects the course of the illness, treatment and recovery process, the interaction of the patient during the treatment process, the selection of coping strategies, the type of relationships with people, and receiving social support. The diagnosis of depression in cancer patients is often difficult, as many symptoms of depression are manifested in a fuzzy and non-characteristic way or are superimposed on the symptoms associated with cancer and/or its treatment. 
Among the causes of psychological depressive disorders in patients with cancer the most frequently mentioned are as follows: a sense of threat to life, uncertainty about the present and future, loss of control over one's own life and an insufficient amount of information on the disease and its treatment possibilities, and changes in one's appearance caused by the illness and treatment. Depression is also strengthened by a sense of helplessness and powerlessness in the face of illness and an inability to affect it. A sense of lack of control and inability to influence the disease intensify depression and contribute to the establishment and preservation of destructive coping strategies [4-7]. Additional causes of depression in cancer patients mentioned in literature are as follows: young age, gender (women are more likely to develop depression), low socio-economic status, lack of support from partner and abnormal relationship with him/her and cancer phobia, inability to fulfil previous social roles and the need to withdraw from society, deterioration of one's financial situation, and disturbance of existing family relationships [7, 8].

Depression in cancer patients can be unambiguously identified if (1) there are at least: (1.1) one key symptom: persistent sadness or low mood and/or loss of interest or pleasure, fatigue; (1.2) two accompanying symptoms: sleep disturbances, reduced attention span, low confidence, poor or increased appetite, suicidal thoughts or acts of suicide, agitation or psychomotor retardation, a sense of wrong/fault or a sense of one's own fault; and (2) the symptoms last for at least 2 weeks $[3,4]$.

Anxiety disorders are quite common in oncological patients especially during the diagnosis and first stages of treatment. Trzebiatowska classifies the causes of anxiety reactions in patients with cancer into three groups: (1) those associated with the cancer (the perception of cancer as an incurable disease, fear of suffering associated with the disease and its treatment, fear of pain, metastases, and premature death); (2) those associated with the treatment process (fear of chemotherapy, radiation therapy and surgery, fear of treatment side effects such as vomiting, weakness, hair loss, mutilation and disfigurement, potency and sexual functioning disorders); and (3) those associated with social functioning and relationships with others (fear of worsening relations with the family, fear of loss of professional and social status, fear of isolation, fear of lack of acceptance and social rejection) [5-7].

The most commonly used tools for the evaluation of anxiety-depressive disorders in oncological patients are: the State and Trait Anxiety Inventory (STAI), the Hospital Anxiety and Depression Scale (HAD), and the Beck Depression Inventory $[5,6]$.
The concept of mental adaptation to disease is based on the cognitive theory and transactional model by Lazarus and Folkman, which assumes that the stress experienced as a result of cancer is not only a result of the physical consequences of the disease but also the result of the cognitive assessment of a stressful situation. This concept defines the adaptation to the disease as "constantly changing cognitive, emotional, and behavioural efforts aimed at mastering the specific external and internal requirements evaluated in terms of stress, aggravating and exceeding existing countermeasures and adaptive capacity of the person" [9]. Greer and Watson determined the model of coping with cancer as comprising five main attitudes regarding cancer: fighting spirit, avoidance/denial, fatalism/stoic acceptance, helplessness/hopelessness, and anxious preoccupation. The theory of adaptation to the disease by Greer and Watson is the basis for the modified Mini-Mental Adjustment to Cancer (MiniMAC) scale [10].

The health locus of control (HLC) and conviction about one's effectiveness in emergency situations is considered one of the most important predictors in the choice of coping strategies applied to chronic illness, including cancer. A health locus of control is indicated by the three major cognitive beliefs: one's own actions, the actions of other people, and chance. The type of health locus of control belief is one of the psychological factors determining the quality of coping with the disease, the choice of health-related behaviour translates into a patient's commitment to the therapeutic process. [11]. Rotter classified health locus of control as internal or external. Internal health locus of control is manifested by assigning a greater responsibility for one's health as the effect of one's behaviour. Those showing dominance of internal health locus of control are more assertive in the doctor-patient relationship, are autonomous in making decisions about their health, and have a higher sense of responsibility for their health. This encourages compliance with treatment recommendations and mobilises patients to take effective health-promoting measures and to persist in them [12]. External health locus of control manifests itself in two attitudes: belief about the influence of others or the belief about the impact of chance on one's health. External health locus of control is conducive to posting the responsibility for one's health to others, which may cause a reduction in self-motivation to take preventive and health-promoting behaviours. External health locus of control is observed more frequently in people with chronic illness. External health locus of control may, however, have a positive impact on the therapeutic process and patient compliance by placing the responsibility for the 
patient's health status and any competence in this field in the hands of the physician $[11,13,14]$.

\section{Aim}

The aim of the study was to assess the psychological functioning of patients with digestive system cancer in the cancer-treating process. Psychological evaluation focused on the analysis of the relationship between anxiety and depression, the type of adaptation strategy, and health locus control. The practical aim of the study was to develop guidelines for psychological care dedicated to this group of patients based on the results of the study.

\section{Material and methods}

A total of 69 patients with digestive system cancer treated in the Gastroenterology Cancer Clinic in Institute of Oncology in Warsaw were examined. The study had received a positive opinion from the Local Ethical Committee and was part of a clinical trial included in the Institute's scientific plan. The study was based on a single, voluntary, and anonymous questionnaire. The reference group, for certain types of analyses, consisted of 532 cancer patients from other hospital wards (aged from 19 to 91 years, average age 54 years).

The study asked the following research questions:

- Do anxiety and depression exhibit a relationship with disease coping strategies in patients with digestive system cancer?

- Do anxiety and depression exhibit a relationship with health locus of control in patients with digestive system cancer?

The study analysed the following variables:

- anxiety, depression;

- disease coping strategies: fighting spirit, positive revaluation, hopelessness-helplessness, anxious preoccupation;

- health locus of control: internal, others, chance.

The study was conducted using a questionnaire consisting of:

- Demographic questionnaire (age, type of illness, type of treatment);

- Hospital Anxiety and Depression Scale (HADS) [15];

- Polish adaptation of Mini-Mental Adjustment to Cancer (Mini-MAC) [16, 17];

- Multidimensional Health Locus of Control (MHLC) [13].

\section{Statistical analysis}

The results were analysed using statistical tests and correlation analysis to assess the strength of the correlation. Kolmogorov-Smirnov test was performed to verify the normal distribution assumption. Levene test was used to verify variances homogeneity. Due to lack of normal distribution, the relationships between the variables were analysed using Kendall's tau-b rank correlation. The differences between the studied group and the reference group was evaluated using Student's t-test with optional Cochran-Cox addendum for non-homogenic variables. In all calculations the significance was set at 5\%. The statistical analysis was performed using SPSS PASW Statistics version 18.

\section{Results}

Sixty-nine patients aged 23 to 91 (average: 56) years were examined. The group consisted of 33 women and 36 men. The reference group, for certain types of analyses, consisted of 532 cancer patients from other hospital wards (aged from 19 to 90 years, mean age of 54 years).

In the analysis of anxiety and depression, it was found that the average severity of anxiety in the patients was 6.70. Low intensity of anxiety occurred in $65 \%$ of patients, the mean intensity of anxiety was observed in $37.5 \%$ of patients, high severity of anxiety was observed in $17.5 \%$ of patients.

Average severity of depression in the patients was 4.83. Low severity of depression occurred in $79.7 \%$ of patients, the mean severity of depression occurred in $5.8 \%$ of patients, and high severity of depression was present in $14.5 \%$ of patients (Table I).

In the analysis of mental cancer-adaptation strategies, it was found that: the average intensity of anxious preoccupation was 15.54 ; the average intensity of a fighting spirit was 23.51; the average intensity of helplessness-hopelessness was 11.81; and the average intensity of positive revaluation was 22.09 (Table II).

Table I. Anxiety and depression - descriptive statistics

\begin{tabular}{lcccc} 
Variable & Min & Max & Average & Std. deviation \\
\hline Anxiety (HADS) & 1 & 19 & 6.70 & 4.191 \\
\hline Depression (HADS) & 0 & 12 & 4.83 & 3.382
\end{tabular}

Table II. Mental adjustment to cancer - descriptive statistics

\begin{tabular}{lcccc} 
Variable & Min & Max & Average & $\begin{array}{c}\text { Std. } \\
\text { deviation }\end{array}$ \\
\hline $\begin{array}{l}\text { Anxious preoccupation } \\
\text { (Mini MAC) }\end{array}$ & 7 & 28 & 15.54 & 5.152 \\
\hline Fighting spirit (Mini MAC) & 15 & 28 & 23.51 & 3.118 \\
\hline $\begin{array}{l}\text { Helplessness-hopelessness } \\
\text { (Mini MAC) }\end{array}$ & 7 & 24 & 11.81 & 3.683 \\
\hline $\begin{array}{l}\text { Positive revaluation } \\
\text { (Mini MAC) }\end{array}$ & 15 & 28 & 22.09 & 3.128
\end{tabular}


Table III. Health locus of control - descriptive statistics

\begin{tabular}{lcccc} 
Variable & Min & Max & Average & $\begin{array}{c}\text { Std. } \\
\text { deviation }\end{array}$ \\
\hline Internal HLC (MHLC) & 14 & 36 & 25.71 & 4.950 \\
\hline Others HLC (MHLC) & 14 & 36 & 26.86 & 5.030 \\
\hline Chance HLC (MHLC) & 9 & 36 & 24.84 & 6.354
\end{tabular}

In the analysis of health locus of control, it was found that: the average severity of the health of the internal control was 25.71, the average severity of the impact of other health amounted to 26,86 , the mean severity of the impact of the case on health amounted to 24.8 (Table III).

Analysis of the differences between studies group and the reference group showed that patients with digestive system cancer showed higher intensity of fighting spirit and lower intensity of helplessness-hopelessness compared with the average cancer patients treated in Oncology Institutes of other clinics (Table IV).

Investigation of relationships between anxiety and depression and mental adjustment to cancer showed: 1) positive correlation between anxiety and depression and anxious preoccupation and hopelessness-helplessness, 2) negative correlation between anxiety and depression and fighting spirit.

Investigation of the relationships between anxiety and health locus of control showed negative correlation between anxiety and depression and internal health locus of control (Table V).

\section{Discussion}

Anxiety disorders in patients with cancer are difficult to diagnose and treat as they often manifest dif-

Table IV. Analysis of differences between studied group and reference group

\begin{tabular}{|c|c|c|c|c|}
\hline \multirow[t]{2}{*}{ Variable } & \multicolumn{4}{|c|}{ Student $t$-test } \\
\hline & $t$ & $\mathrm{~d} f$ & Significance & Mean difference \\
\hline Anxious preoccupation (Mini MAC) & 0.864 & 567 & 0.388 & 0.552 \\
\hline Fighting spirit (Mini MAC) & -2.214 & 567 & $0.027^{\star}$ & -0.907 \\
\hline Helplessness-hopelessness (Mini MAC) & 2.027 & 95.080 & $0.045^{\star}$ & 0.978 \\
\hline Positive revaluation (Mini MAC) & -1.246 & 567 & 0.213 & -0.553 \\
\hline Anxiety (HADS) & 1.643 & 567 & 0.101 & 0.896 \\
\hline Depression (HADS) & 1.252 & 567 & 0.211 & 0.610 \\
\hline Internal HLC (MHLC) & -1.504 & 567 & 0.133 & -0.998 \\
\hline Others HLC (MHLC) & 0.107 & 567 & 0.915 & 0.069 \\
\hline Chance HLC (MHLC) & -0.973 & 567 & 0.331 & -0.759 \\
\hline
\end{tabular}

*Significance $<0.05$.

Table V. Tau-b Kendall correlation of anxiety and depression with MAC and HLC

\begin{tabular}{|c|c|c|c|}
\hline \multicolumn{2}{|l|}{ Variable } & Anxiety (HADS) & Depression (HADS) \\
\hline \multirow[t]{2}{*}{ Anxious preoccupation (Mini MAC) } & Correlation & $0.480^{* *}$ & $0.385^{\star \star}$ \\
\hline & Significance & $<0.001$ & $<0.001$ \\
\hline \multirow[t]{2}{*}{ Fighting spirit (Mini MAC) } & Correlation & $-0.378^{\star \star}$ & $-0.196^{\star}$ \\
\hline & Significance & $<0.001$ & 0.027 \\
\hline \multirow[t]{2}{*}{ Helpless-hopeless (Mini MAC) } & Correlation & $0.495^{\star *}$ & $0.430^{\star *}$ \\
\hline & Significance & $<0.001$ & $<0.001$ \\
\hline \multirow[t]{2}{*}{ Cognitive avoidance (Mini MAC) } & Correlation & -0.114 & -0.109 \\
\hline & Significance & 0.197 & 0.218 \\
\hline \multirow[t]{2}{*}{ Internal HLC (MHLC) } & Correlation & $-0.221^{\star}$ & $-0.278^{\star \star}$ \\
\hline & Significance & 0.011 & 0.001 \\
\hline \multirow[t]{2}{*}{ Others HLC (MHLC) } & Correlation & -0.170 & -0.103 \\
\hline & Significance & 0.051 & 0.238 \\
\hline \multirow[t]{2}{*}{ Chance HLC (MHLC) } & Correlation & -0.054 & -0.086 \\
\hline & Significance & 0.535 & 0.324 \\
\hline
\end{tabular}

${ }^{*}$ Significance $<0.05,{ }^{* *}$ significance $<0.01$. 
ferently than in patients with other psychosomatic disorders. Oncological patients with high anxiety often do not show depressed mood. An additional difficulty in diagnosis is that patients do not always realise that the emotional state they are experiencing is anxiety and so they have a problem naming it. Therefore, often the only diagnostic criteria are the symptoms of somatisation or intensification of other symptoms such as primary cancer pain [5]. It is therefore essential to quickly diagnose anxiety disorders and implement proper psychological care and pharmacological treatment, since it prevents the deterioration of the patient's functioning in the physical, psychological, and social areas $[2,15]$.

In the studied group of patients the mean intensity of anxiety was not significantly different compared to the reference population of patients with cancer other than the gastrointestinal tract [16]. This result is very satisfactory because it indicates good mental health of the patients in comparison with results of Jadoon et al., who found that patients with gastrointestinal cancer and breast cancer show higher intensity of anxiety compared with patients with other cancer patients. Jadoon examined 150 patients, and the average cancer patients age was 40.85 years, the average age in the control group was 39.58 years [17]. The study used the Aga Khan University Anxiety and Depression Scale. The discrepancies in the results of the studies may result from the use of a tool to study anxiety and depression other than used in our study, or other variables not captured [18].

The obtained research results on the correlation of anxiety and depression with mental adaptation to cancer indicate that: 1) the higher the severity of anxiety and depression, the higher the severity of anxious preoccupation and helplessness-hopelessness; and 2) the lower the severity of anxiety and depression, the higher the intensity of a fighting spirit.

Our findings correspond with clinical reports and theoretical analysis as well as with the results of other published studies. According to de Walden-Gałuszko, depression is often observed in the states of impaired adaptation to the disease, which are characterised by excessive worry, anxiety, depressed mood, feelings of helplessness, and a limited ability to perform daily activities $[5,15]$. According to Kubler-Ross, depression is one of the five stages of mental adaptation to cancer. Kubler-Ross treated depression as a physiological disease adaptation step [19]. According to Watson and Greer, cancer-coping attitudes, such as fatalism, stoic acceptance, anxious preoccupation, and helplessness-hopelessness, are associated with depression. Moreover, the attitude of helplessness-hopelessness is associated with a high risk of depression and shorter survival [17]. It was also found that the attitude focused on avoiding is also associated in the long-term with the occurrence of depression [20]. In studies by Thomé and Hallberg, avoidance attitude increases perceived physical symptoms severity, especially cancer pain, and increases the risk of the occurrence of depression. The avoidance attitude has an adverse impact on the patient's therapeutic relationship with medical staff, contributes to patient's non-compliance with a treatment regimen and the presence of more risky health behaviours, and reduces the possibility of remission of depression [21].

Watson found that an attitude of helplessnesshopelessness, and anxious preoccupation, correlated positively with anxiety and depression. The study used the Mini-MAC Scale (Mini-Mental Adjustment to Cancer Scale) to measure coping strategies and Emotion Control-CECS (Courtauld Emotional Control Scale) to measure anxiety and depression. The study was conducted on 308 women in the early stages of breast cancer [17].

Elani and Allison found an association of avoidance attitudes and depression 157 patients with head and neck cancer were examined in the period of 6-12 months from diagnosis. Patients with higher levels of depression had used the strategy of accusing themselves, wishful thinking, and avoidance. Depression was measured using HADS, and coping strategies were measured using WCC (Ways of Coping Checklist) [22].

Johansson et al. found that patients with high intensity of helplessness-hopelessness and anxious preoccupation showed higher levels of depression. Ninety-five patients with head and neck cancer were examined one month and 12 months after initiation of treatment and during the terminal stage of the illness (an average of about 4.2 years). Cancer coping strategies were measured using Scale Mini-MAC. Depression was measured using HADS [23].

Andritsch et al. found a correlation of anxious preoccupation with depression. A total of 210 patients with breast cancer were examined during the period of 1-5 years from diagnosis. Depression was measured using BSI (Brief Symptom Inventory) and IES (Impact of Event Scale), and coping strategies were measured using Mini-MAC and the Perceived Family Support (PFS) [24].

Studies by Laarhoven et al. found that active strategies: fighting spirit and attitude of acceptance of the disease, were associated with low levels of symptoms associated with anxiety and depression compared with passive attitudes. Ninety-two cancer patients during causal treatment and 59 patients during palliative treatment were examined. Disease coping strategies were measured using COPE-E (COPE-Easy abbreviated 
version), and depression was measured using BDI (Beck Depression Inventory for Primary (are) and Beck Hopelessness Scale. In both groups, active strategies and acceptance of illness brought improved quality of life, and reduction in depression and resignation [25].

The obtained research results on the correlation of anxiety and depression with health locus of control show that the lower the severity of anxiety and depression, the higher the severity of internal health locus of control.

Many publications, stress that emotional reactions due to the stress of the disease are more adaptive and less severe when the person believes that they have an internal control of their life.

Studies by Abramowitz confirmed a link between depression and external health locus of control. It had further been found that people with a low tendency for depression have relatively high internal control. Studies by Molinari and Khanna found that depression correlates negatively with internal health locus of control. They showed that the outer locus of control is not only significantly associated with depression, but also with anxiety and reluctance [26].

\section{Conclusions}

The study did not cover the undertaken subject fully. It would be worth while to carry out a similar study on a larger population of patients with cancer of the digestive system treated in other clinical centres.

The results indicate that anxiety-depressive disorders are related to destructive coping strategies and external health locus of control.

The obtained conclusions confirm the necessity of psychological support of cancer patients showing evidence of destructive attitudes and external health locus of control, so that the severity of anxiety-depressive disorders can indirectly be reduced. It seems like a good idea to create prevention programs and take appropriate action to improve their effectiveness, and to facilitate the development of skills used to cope with stress and difficult situations, among people whose professional future is associated with medicine. It seems reasonable to conduct educational courses and interpersonal training focusing on the above themes and to include them in the medical studies curriculum.

\section{References}

1. Woźniewski M. 1. Physical culture in the lives of people with cancer [Polish]. Adv Clin Exper Med 2002; 11: 103-8.

2. Dorfmuller M. Methods of disease processing and emotional stress reduction. In: Psychooncology. Diagnostics - therapeutic methods [Polish]. Dorfmuller M, Dietzfelbinger $\mathrm{H}$ (eds.). Urban \& Partner, Wrocław 2011; 159-62.
3. Pużyński S, Beresewicz M. 3. Principles of diagnosis and treatment of mental disorders. In: Psychology [Polish]. Strelau J (ed.). GWP 2000; 493-512.

4. Bilikiewicz A, Strzeżyński W. Psychiatry [Polish]. PZWL, Warsaw 1997.

5. Trzebiatowska I. Psychiatric disorders in cancer. In: Psychooncology [Polish]. Walden-Gałuszko K (ed.). Polish Psychiatry Library. 2000; 71-81.

6. Trzebiatowska I. 6. Anxiety disorders in cancer - a practical aspect. In: Psychooncology [Polish]. Walden-Gałuszko K (ed.). Polish Psychiatry Library 2000; 49-53.

7. Bowers L, Boyle D. Depression in patients with advanced cancer. CJON 2003; 7-3: 281-8.

8. Harrison J, Maguire P. Influence of age on psychological adjustment to cancer. Psychooncology 1995; 4: 33-8.

9. Lazarus RS, Cohen JB. Environmental stress. In: Human behavior and environment. Altman I, Wohlwill JF (eds.). Plenum 1977.

10. Greer S, Watson M. Mental adjustment to cancer: its measurement and prognostic importance. Cancer Surv 1987; 6: 439-53.

11. Wrześniewski K. Psychological conditions of formation and development of somatic diseases. In: Psychology [Polish]. Strelau J (ed.). GWP 2001.

12. Rotter JB. Social learning and clinical psychology. Engelwood Cliffs. N.J. Prentice Hall 1954.

13. Juczyński Z. Multidimensional Health Locus of Control Scale - MHLC. In: Measurement tools in health promotion and psychology [Polish]. Laboratory of Psychological Tests, Polish Psychological Association, Warsaw 2001.

14. Juczyński Z. Beliefs and expectations as the determinants of health-related behaviors. In: Personal and social resources conducive to the health of individuals [Polish]. Juczyński Z, Ogińska-Bulik N (ed.). WUŁ 2003; 49-61.

15. Walden-Gałuszko K, Majkowicz M. Quality of life in cancer [Polish]. Wydawnictwo Uniwersytetu Gdańskiego 1994; 89164.

16. Juczyński Z. Measurement tools in health promotion and psychology [Polish]. Laboratory of Psychological Tests, Polish Psychological Association, Warsaw 2001.

17. Watson M, Greer S, Young J, et al. Development of a questionnaire measure of adjustment to cancer: the MAC scale. Psychol Med 1988; 18: 203-9.

18. Jadoon N, Munir W, Shahzad M, et al. Assessment of depression and anxiety in adult cancer outpatients a cross-sectional study. BMC Cancer 2010; 10: 594.

19. Kubler-Ross E. Talks about death and dying [Polish]. Media Rodzina, Poznan 1979.

20. Greer S. CBT for emotional distress of people with cancer: some personal observations. Psychooncology 2008; 17: 170-3.

21. Thomé B, Hallberg I. Quality of life in older people with cancer - a gender perspective. Eur I Cancer Care 2004; 13: 454-63.

22. Elani HW, Allison PJ. Coping and psychological distress among head and neck cancer patients. Support Care Cancer 2011; 19: 1735-41.

23. Johansson R, Mohr D, Andersson D, et al. Self-guided psychological treatment for depressive symptoms: a meta-analysis. PLoS One 2011; 6: e21274. 
24. Andritsch E, Dietmaier G, Hofmann G, et al. Global quality of life and its potential predictors in breast cancer patients, an exploratory study. Support Care Cancer 2007; 15: 21-30.

25. Laarhoven HW, Schilderman J, Bleijenberg G, et al. Coping, quality of life, depression, and hopelessness in cancer patients in a curative and palliative, end-of-life care setting. Cancer Nursing 2011; 34: 302-14.

26. Molinari V, Khanna P. Locus of control and its relationship to anxiety and depression. J Personal Assessment 1981; 45: 314-9.

Received: 23.04 .2014

Accepted: 10.07.2014 